\title{
Dom Casmurro por John Gledson: notas de rodapé do tradutor como literatura de viagem
}

\author{
Cynthia Beatrice Costa*
}

\begin{abstract}
Resumo
Partindo do princípio de que é possível traçar paralelos entre o tradutor e o viajante (NEUMANN, 2013), o presente artigo propõe uma inter-relação entre notas de rodapé redigidas por tradutores literários e a literatura de viagem, entendida aqui em sentido abrangente e heterogêneo (YOUNGS, 2013). Apresenta, para tanto, uma breve análise de 20 das 64 notas de rodapé assinadas pelo tradutor inglês John Gledson em sua tradução do romance Dom Casmurro (1899), do brasileiro Joaquim Maria Machado de Assis. A hipótese apresentada é a de que o tradutor de literatura pode participar ativamente do estabelecimento de contato entre leitores e um outro lugar/ outra cultura por meio de suas notas, integrando-as, desse modo, ao gênero literatura de viagem.

Palavras-chave: Dom Casmurro. Machado de Assis em inglês. John Gledson. Tradução literária. Literatura de viagem.
\end{abstract}

\footnotetext{
* Universidade Federal de Uberlândia (UFU). Professora do bacharelado em Tradução da Universidade Federal de Uberlândia (UFU), membro da PósGraduação em Estudos Literários (PPLET/UFU) e da Pós-Graduação em Estudos da Tradução (PGET/UFSC). ORCID: http:// orcid.org/0000-00023063-0121.
}

Cadernos CESPUC de Pesquisa. Série Ensaios. n.38, 10 Sem./2021, p. 63-80. e-ISSN: 2358-3231 (OJS). Recebido em: 01/07/2021. Aceito em: 25/08/2021. 


\title{
John Gledson's Dom Casmurro: translator's footnotes as travel writing
}

\author{
Cynthia Beatrice Costa
}

\begin{abstract}
Assuming that it is possible to draw parallels between translators and travelers (NEUMANN, 2013), this paper proposes an interrelationship between footnotes written by literary translators and travel writing, used here in a broad and heterogeneous sense ( YOUNGS, 2013). It presents, therefore, a brief analysis of 20 of the 64 footnotes signed by the English translator John Gledson in his translation of the novel Dom Casmurro (1899), by Brazilian author Joaquim Maria Machado de Assis. By doing so, it examines the hypothesis that literary translators can actively participate in establishing a contact between readers and another place/culture through their notes, thus integrating them into the travel writing genre.
\end{abstract}

Keywords: Dom Casmurro. Machado de Assis in English. John Gledson. Literary translation. Travel writing.

Cadernos CESPUC de Pesquisa. Série Ensaios. n.38, 10 Sem./2021, p. 63-80. e-ISSN: 2358-3231 (OJS). Recebido em: 01/07/2021. Aceito em: 25/08/2021. 
Há 64 notas de rodapé na tradução de John Gledson do romance Dom Casmurro (1899), de Joaquim Maria Machado de Assis. A média é de cerca de uma nota a cada 4,5 páginas, aparentemente alta para os padrões editoriais de literatura traduzida. O projeto tradutório de Gledson (1997) envolveu o desejo de contextualizar histórica e geograficamente o romance machadiano, como ele explica em sua introdução: "dar alguma ideia da geografia - física e social - do Rio de Janeiro de fins do século XIX"1 (GLEDSON, 1997, p. xxv).

Como paratexto ${ }^{2}$ de um romance, a descrição da geografia física e social de um lugar distante no tempo e no espaço - o Rio de Janeiro do século XIX - pode remeter ao que se compreende como literatura de viagem. Não porque envolva o relato de uma viagem realizada, mas porque contém o testemunho (no caso, do tradutor) a respeito daquele lugar. É por esse viés que o presente texto se propõe a traçar uma relação entre as notas de rodapé do Dom Casmurro traduzido por Gledson e esse gênero literário não ficcional.

Descrições de deslocamentos e de lugares estrangeiros, distantes e/ou exóticos, e das experiências vividas neles, estão, em geral, no núcleo do que se entende por literatura de viagem. Como expõe Youngs (2013, p. 1), porém, esse gênero mostra-se com frequência heterogêneo e refratário, dificilmente restrito a apenas um tipo de texto. É por isso que parece viável examinar a hipótese de que notas de rodapé redigidas por um tradutor no contexto de um romance proveniente de outro lugar, outra cultura, outro povo, possam se encaixar nele.

Não é incomum o paralelo entre tradução e viagem; a tradução pode ser entendida como "trânsito": "Uma vez existindo uma tradução, uma passagem de uma realidade para outra, sempre haverá um trânsito deste para aquele, tanto daquele que está inserido no contexto traduzido como por parte daquele que busca a situação traduzida" (NEUMANN, 2013, p. 147).

Assim como a viagem, a tradução "pode produzir violência ou cooperação, conflito ou intercâmbio"3 (YOUNGS, 2013, p. 10), ademais, viagens implicam traduções culturais e/ou linguísticas. Tanto viajantes quanto tradutores movem-se entre culturas, podendo promover aproximações ou afastamentos.

\footnotetext{
1 Estas e outras citações foram traduzidas por mim: "to give some idea of the geography - physical and social - of Rio de Janeiro in the late nineteenth century".

2 Entendido aqui como produção verbal de acompanhamento do texto principal. (GENETTE, 2009, p. 9).

3 can produce violence or cooperation, conflict or exchange
}

Dom Casmurro por John Gledson: notas de rodapé do tradutor como literatura de 65 viagem 
Apesar da variedade textual que o termo guarda-chuva "literatura de viagem" pode abranger - de relatórios etnográficos a cartas, de resenhas de viagem publicadas em jornais a diários íntimos -, um ponto comum a ser levado em conta é que o relato não pode ser totalmente imaginativo, isto é, pressupõe-se que não seja inventado. Como frisa Youngs (2013, p. 5), com base em Peter Hulme, trata-se de literatura, mas não de ficção - é preciso que o leitor confie no que está sendo relatado.

Outro ponto relevante é a abordagem que os estudos pós-coloniais trouxeram à literatura de viagem, colocando em xeque possíveis olhares imperialistas e racistas e rompendo com a ilusão de que relatos de viagem podem ser neutros e objetivos (YOUNGS, 2013, p. 9). Pratt (1992, p. 5), por exemplo, investiga como a escrita de viagem e de desbravamentos produziu a noção de "resto do mundo"4 para leitores europeus. Isso não significa, porém, que não exista uma literatura de viagem autorreflexiva, capaz de desconfiar da própria percepção e problematizá-la (BASSNETT, 2004, p. 225; YOUNGS, 2013, p. 76).

Em suma, pode-se elencar algumas características-chave da literatura de viagem sobre as quais se baseiam a escolha das notas de rodapé analisadas neste texto e a discussão sugerida a partir delas. São características relevantes: abordar deslocamentos e/ou lugares; não ser ficcional; despertar confiança por parte do leitor; expressar uma determinada postura ideológica com relação ao "outro" retratado (de forma consciente ou não).

Este texto está dividido em outras três partes. No próximo item, fala-se de Gledson como tradutor e crítico machadiano e de sua empreitada tradutória em Dom Casmurro; depois, é brevemente problematizado o uso de notas de rodapé na tradução literária e apresentada a análise de notas do tradutor selecionadas para examinar de que modo podem se assemelhar à chamada literatura de viagem. Fecha-se com considerações finais.

\section{John Gledson e seu Dom Casmurro}

John Gledson é professor aposentado da Universidade de Liverpool, onde atuou na área de estudos brasileiros. Além de Machado de Assis, ele traduziu para a língua inglesa obras literárias de Milton Hatoum e Ruy

4 the rest of the world 
Castro, entre outros. Ao longo das últimas quatro décadas, tornou-se um célebre crítico machadiano dentro e fora do Brasil, passando também temporadas no país sul-americano. Grande defensor da obra machadiana como meio de acesso à história brasileira oitocentista, ele afirma:

Há quase duas décadas que este assunto me fascina. De fato, posso dizer que aprendi história do Brasil com Machado de Assis. Claro que Machado nunca escreveu um livro, um artigo que fosse, de "pura" história, mas nas suas obras de ficção, e nas suas crônicas, há uma profusão de referências à história brasileira que nos dão acesso a um pensamento complexo, sutil, mutável, e que sabia acomodar dúvidas e ironias. (GLEDSON, 2006, p. 293).

Gledson compartilha a abordagem histórico-sociológica da obra de Machado com Roberto Schwartz - inclusive, entre outros textos, traduziu para o inglês, em 2001, o livro Um mestre na periferia do capitalismo (1990), contribuição canônica de Schwartz à crítica machadiana, como $A$ Master on Periphery of Capitalism: Machado de Assis (Post-Contemporary Interventions). A respeito do impacto que o estudioso brasileiro teve sobre seu pensamento, referindo-se às suas primeiras experiências com a literatura de Machado fim da década de 1970, o tradutor declarou:

Não sei se tinha gostado ou não, mas certamente não tinha entendido nada. Acho que naquele momento houve duas coisas que se juntaram: uma foi a leitura do que é certamente o livro mais importante sobre Machado a ser escrito nos últimos 50 anos, mais de 50 anos: o livro de Roberto Schwarz, Ao Vencedor as Batatas, que dá a chave para entendermos os primeiros romances de Machado de Assis. E de entendê-los através de um simples conceito, que é o conceito do favor e das relações de favor, que tipificam até hoje, de certa maneira, a sociedade brasileira - e que são óbvios quando a gente os vê, mas o paradoxo é que são tão óbvios, que a gente não os vê; às vezes, ficam tão perto de nós, que a gente não os nota. (GLEDSON, 2005).

Seus estudos posteriores dialogam fortemente com o que Gledson aprendera com Schwartz a respeito do funcionamento da sociedade brasileira retratada por Machado em sua obra. Entre os encontrados em forma de livro, estão The Deceptive Realism of Machado de Assis: A

Dom Casmurro por John Gledson: notas de rodapé do tradutor como literatura de 67 viagem 
Dissenting Interpretation of Dom Casmurro (1984), traduzido no Brasil, sete anos depois, por Fernando Py como Machado de Assis: Impostura e Realismo; Machado de Assis: ficção e história (1986), publicado pela editora brasileira Paz e Terra, com tradução de Sônia Coutinho, que aproxima em estrutura e tema Dom Casmurro da novela machadiana - ou romance, como argumenta Gledson - Casa Velha (1885); e Por um novo Machado de Assis (2006). No Brasil, Gledson também organizou a antologia 50 Contos de Machado de Assis, de 2007, e uma série de coletâneas de crônicas para a Editora da Unicamp, em 2008, mesmo ano em que foi lançada a sua tradução de uma seleção de contos machadianos intitulada A Chapter of Hats - Selected Stories, pela editora londrina Bloomsbury.

Em 1997, a tradução de Gledson de Dom Casmurro foi lançada pela Oxford University Press, maior editora universitária do mundo, com filiais na Inglaterra e nos Estados Unidos. Terceira tradução oficial do romance para a língua inglesa - sendo as outras duas da estadunidense Helen Caldwell (1953) e do escocês Robert Scott-Buccleuch (1991) -, sua empreitada diferenciou-se intencionalmente das anteriores, já que considerava ambas problemáticas (GLEDSON, 2005; GLEDSON, 2013, p. 239).

Em seu projeto literário como tradutor crítico de Machado, Gledson enfatiza o que se apreende da história do Brasil na obra do escritor, entendido por ele como um realista: as relações entre as classes sociais, a fundação de um país independente e a decadência da sociedade patriarcal. Essa ênfase resulta, por vezes, em uma tendência explicativa, no sentido de elucidar o conteúdo do texto na tradução (e nas notas de rodapé, como se verá adiante). Para ele, Dom Casmurro é um retrato das relações de poder e de favor que caracterizaram a sociedade carioca oitocentista, salientadas, sobretudo, na figura do agregado José Dias. Não é o aspecto psicológico de um narrador (Bentinho/Casmurro) que descreve a ascensão e queda de seu romance com a vizinha mais pobre (Capitu) que mais lhe interessa.

Conhecedor profundo da língua portuguesa brasileira e viajante experiente por estas terras sul-americanas, Gledson dedica espaço extraliterário à disseminação de seus conhecimentos:

John Gledson, além de especialista em literatura brasileira, é um grande conhecedor da história e da cultura brasileiras, com as quais estabelece paralelo constante em sua crítica e sua prática tradutória. As traduções e os livros escritos 
e organizados por Gledson são acompanhados de prefácios e notas ricamente ilustrados, nos quais ele esmiúça o estilo e o ritmo do autor, além de fornecer ao leitor um panorama cultural, social e político da época em que a obra foi escrita. (FREITAS, 2012, p. 89).

Assim, é de se esperar que, em sua tradução e nos paratextos que a acompanham, Gledson realce o aspecto sociocultural e histórico do texto machadiano. A estratégia de adotar notas de rodapé em abundância certamente tem relação com isso:

O comentário de um colega de Liverpool, que leu Machado por curiosidade e que não é especialista em língua portuguesa, embora leia português, apoia minha opinião de que é necessário dar mais ajuda aos leitores, sem sobrecarregar o texto com demasiadas notas. (GLEDSON, 2006, p. 283).

É nesse sentido, de "dar mais ajuda aos leitores", que se pode levantar a hipótese de que suas notas possuem um caráter de literatura de viagem compartilhando semelhanças com guias de viagem e outros tantos tipos de texto que compõem um gênero tão diversificado (YOUNGS, 2013, p. 1).

\section{Notas do tradutor como literatura de viagem}

Com base nas considerações teóricas já citadas, é proposta, a seguir, uma breve análise de 20 notas do tradutor encontradas na tradução de Dom Casmurro realizada por Gledson (1997).

É relativamente recente a atenção dada às notas do tradutor no âmbito dos Estudos da Tradução. Em Paratextos editoriais, originalmente publicado em 1987, Gérard Genette (2009) cita as notas do tradutor como um tipo de paratexto editorial. Em Notas do tradutor e processo tradutório, Solange Mittmann (2003) sugere um aprofundamento no assunto, ressaltando tanto a escassez de estudos sobre notas do tradutor como a escassez das próprias notas, que seria baseada em uma visão conservadora da tradução e da leitura de literatura: "As N.T. [notas do tradutor] têm sido negadas, ou ferrenhamente criticadas, pelos adeptos de uma concepção tradicional

Dom Casmurro por John Gledson: notas de rodapé do tradutor como literatura de 69 viagem 
sobre a tradução, como um barulho que incomoda" (MITTMANN, 2003, p. 107).

Parece intrigante a implicância dirigida à presença de notas, acusando-as de "barulho", distração ou até intrusão no texto literário. $\mathrm{O}$ interesse que se tem por notas de rodapé e a possível interrupção que causam à leitura - ou nenhuma interrupção, caso se opte por não as ler - dependem do leitor e do tipo de leitura que se faz. Para estudiosos do romance, por exemplo, as notas podem ser de grande serventia.

Remetendo-se a Eugene Nida, Mittmann aborda a nota do tradutor como um recurso explicativo e de acréscimo. Sua função seria "de acrescentar informações que possam ser úteis - para a compreensão do contexto histórico-social e de corrigir discrepâncias linguísticas e culturais" (MITTMANN, 2003, p. 115). Essa abordagem está de acordo com o que é proposto por Gledson em sua tradução de Dom Casmurro (1997), assim como a ideia de que as notas abrem uma "janela" - no caso, uma janela para o Brasil: "a N.T. é citada juntamente com um pequeno trecho do texto, onde se abre a 'janela' para a nota, que marcamos com o uso de um asterisco" (MITTMANN, 2003, p. 116).

Sob o ângulo da literatura de viagem, as notas também podem ser consideradas uma forma de tradução. Ao traduzir o Brasil de Machado para o leitor, Gledson produz uma espécie de relato de viagem; uma tradução de sua experiência com o país estrangeiro. Neumann argumenta:

No momento em que o viajante, o imigrante, o aventureiro escreve sobre o que viu, ou seja, representa, reproduz o que é a sua leitura do vivenciado, registrase a tradução da experiência, daquilo que viu para que o mesmo possa ser compreendido pelo leitor diante daquela realidade (NEUMANN, 2013, p. 150).

Tudo isso não exclui, porém, uma possível visão crítica que se possa ter no que diz respeito às notas de Gledson em Dom Casmurro (1997). Como lembra Mittmann, notas do tradutor nem sempre são vistas como um recurso apropriado. Ela resgata o artigo "Quando se justifica e quando se impõe um comentário do tradutor" (1979), em que Agenor Soares do Santos listou como injustificável, por exemplo, a nota que "faz pouco da inteligência do leitor ou, mais grave ainda, do autor, e 'explica' o que se deduz sem dificuldade do texto" (MITTMANN, 2003, p. 5). 
$\mathrm{Na}$ introdução à sua tradução, Gledson (1997, p. xxv) justifica seu uso de notas como uma maneira de "reduzir a distância do leitor da língua inglesa moderna de um romance que é, no fim das contas, um drama doméstico e que, como vimos, não pode ser explícito ou explicativo

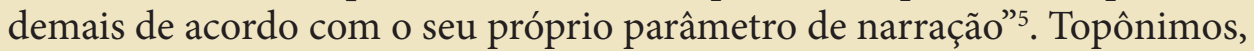
singularidades da história e da cultura brasileiras, assim como referências bíblicas, literárias e mitológicas, formam, ao todo, 64 notas na edição, das quais 33 remetem diretamente ao Brasil. Há notas que poderiam, até mesmo, ser classificadas como conhecimentos gerais, como a indicação de que Tétis é mãe de Aquiles na mitologia grega (GLEDSON in ASSIS, 1997, p. 64) e de que Santa Mônica é a mãe de Santo Agostinho e responsável por sua conversão (GLEDSON in ASSIS, 1997, p. 100). Nesses casos, as notas ganham um caráter mais de curiosidade do que de esclarecimento - ou, no pior dos cenários, de subestimação dos conhecimentos do leitor.

Seria difícil negar o caráter subjetivo da justificativa para se inserir ou não uma nota. Como se verá no quadro adiante, pode haver explicações que denunciam certa noção de um Brasil excessivamente exótico e distante. Talvez possa ser detectada uma tendência etnocêntrica, comum em traduções de literaturas periféricas (no caso, a brasileira) para países de cultura dominante (no caso, Estados Unidos e Inglaterra).

Etnocêntrico significará aqui: que traz tudo à sua própria cultura, às suas normas e valores, e considera o que se encontra fora dela - o Estrangeiro - como negativo, ou, no máximo, bom para ser anexado, adaptado, para aumentar a riqueza desta cultura (BERMAN, 2012, p. 39).

Por outro lado, Gledson parece cônscio de seu papel como tradutor não apenas de um texto, mas de uma cultura; há uma clara preocupação em entender o contexto em que se insere o romance, o que é característica da tradução dita "cultural":

A tradução cultural é estabelecida a partir da necessidade de definição de determinado contexto, quando se constrói um terceiro espaço, diferente do até então conhecido, [...] a partir do momento em que este é absorvido pelo elemento novo, pelo viajante, imigrante ou aventureiro (NEUMANN, 2013, p. 151).

5 to reduce the modern English-language reader's distance from a novel that is, after all, a domestic drama, and that, as we have seen, cannot within its own parameters of narration be too explicit our explanatory

Dom Casmurro por John Gledson: notas de rodapé do tradutor como literatura de 71 viagem 
Para o presente trabalho, foram selecionadas 20 notas da tradução de Gledson, pois, ao descreverem monumentos, espaços urbanos e possíveis "destinos", parecem se aproximar mais do que se pode considerar como um relato de viagem. A seguir, elas são comentadas uma a uma:

\section{Quadro 1 - Análise das notas}

\begin{tabular}{|c|c|c|}
\hline Nota do tradutor & Tipo de nota & Considerações \\
\hline $\begin{array}{l}\left.\text { Engenho } \operatorname{Novo}^{*} \text { (p. } 3\right) \\
{ }^{\star} A \text { recently developed suburb of } \\
\text { Rio de Janeiro, some six miles } \\
\text { from the center. }\end{array}$ & Explicação de topônimo. & $\begin{array}{l}\text { O primeiro de muitos } \\
\text { topônimos explicados. Não } \\
\text { fica claro se o Engenho Novo } \\
\text { era recentemente desenvolvido } \\
\text { à época do romance ou se o era } \\
\text { na década de 1990, quando da } \\
\text { publicação da tradução. }\end{array}$ \\
\hline $\begin{array}{l}\text { Petrópolis* (p. 3) } \\
{ }^{*} \text { Petrópolis is a city about twenty } \\
\text { miles from Rio de Janeiro, situated } \\
\text { in the mountains overlooking } \\
\text { Guanabara Bay. Because of its } \\
\text { relatively cool and healthy climate, } \\
\text { away from the dangers of yellow- } \\
\text { fever, it was a place of refuge for the } \\
\text { rich during the summer months, } \\
\text { and it was linked to the capital by } \\
\text { the country's first railway. From } \\
\text { the mid-century on, Pedro II } \\
\text { encouraged German immigration } \\
\text { to the city - thus the names of } \\
\text { such areas as Renânia (literally, } \\
\text { Rhineland). }\end{array}$ & $\begin{array}{l}\text { Explicação de dois } \\
\text { topônimos: Petrópolis e } \\
\text { Renânia - esta segunda é } \\
\text { citada pelo narrador logo } \\
\text { a seguir de Petrópolis. }\end{array}$ & $\begin{array}{l}\text { Este é um caso de nota que } \\
\text { apresenta um caráter quase de } \\
\text { guia de viagem, alongando-se } \\
\text { na descrição de um destino na } \\
\text { região fluminense. }\end{array}$ \\
\hline $\begin{array}{l}\text { casuarina tree }{ }^{\star}(\mathrm{p} .5) \\
{ }^{\star} \text { A tree of Australia and Indian } \\
\text { origin, similar to a long-needled } \\
\text { pine in appearance. }\end{array}$ & $\begin{array}{l}\text { Explicação de espécie } \\
\text { vegetal. }\end{array}$ & $\begin{array}{l}\text { Um caso de explicação que } \\
\text { remete ao relato de viagem à } \\
\text { maneira das expedições. }\end{array}$ \\
\hline
\end{tabular}


I might write a History of the Suburbs, less dry than the memoir Father Luis Gonçalves dos Santos wrote about the city of Rio itself.* (p. 6)

${ }^{\star} A$ reference to the Memórias Para Servir à História do Reino do Brasil (Memoirs to Contribute to the History of the Kingdom of Brazil), which recounts in great detail events in the country during the period when King John VI of Portugal had his court in Rio de Janeiro (1809-1821).
Explicação histórica.
Além da explicação do contexto, pode-se propor outro paralelismo com a literatura de viagem, no próprio romance: $o$ narrador declara uma intenção inicial - abandonada em prol do relato de sua história pessoal - de escrever uma "História dos Subúrbios do Rio de Janeiro". Mesmo quando se pretende falar de um lugar, pode-se acabar falando de si mesmo.
Itaguaí (p. 11)*

${ }^{*} A$ town about forty miles west of Rio de Janeiro, on the low-lying land near the ocean. Bento's father would have been a sugar planter.
Explicação de topônimo acrescida de possível interpretação sobre o romance.
Corcovado* (p. 24)

*The high mountain to the South of the center of Rio de Janeiro, on which the famous statue of Christ the Redeemer now stands.
Explicação de marco geográfico.
O tradutor "adivinha" aqui o possível negócio do pai de Bento, plantação de cana-deaçúcar.

Muitas questões poderiam derivar de uma análise crítica desta específica nota. Duas, a princípio, se destacam: 1) a explicação do que é "Corcovado", pode-se subentender que $\mathrm{o}$ tradutor imagina ser esse um ícone carioca desconhecido pelo leitor; 2) o Cristo Redentor começou a ser construído mais de meio século após a época da narrativa (década de 1870). Ao esclarecer que o Cristo Redentor fica hoje sobre essa montanha, Gledson localiza o leitor no espaço atual do Rio, mas, ao mesmo tempo, talvez $o$ afaste do espaço em que se passa a narrativa - o Cristo não estava sobre a montanha no cenário de Dom Casmurro. 


\begin{tabular}{|c|c|c|}
\hline $\begin{array}{l}\left.\text { ten } \text { contos }^{*} \text { (p. } 31\right) \\
{ }^{*} \text { At that time (1857) ten contos } \\
\text { would have been equivalent to } \\
\$ 5,400 \text { (1,100 pounds). One } \\
\text { thousand mil-réis made one conto. } \\
\text { Based on the average sale price for } \\
\text { male slaves aged } 20 \text { to } 25 \text { in the } \\
\text { coffee-rich town of Vassouras in } \\
\text { the mid } 1850 \text { s, ten contos would } \\
\text { have purchased seven slaves (at } \\
\text { one conto, } 400 \text { mil-réis each), } \\
\text { with something left over. }\end{array}$ & $\begin{array}{l}\text { Explicação de } \\
\text { singularidade histórica. }\end{array}$ & $\begin{array}{l}\text { Esta nota apresenta conteúdo } \\
\text { marcadamente extratextual, } \\
\text { o que sugere mais a respeito } \\
\text { do olhar do tradutor como } \\
\text { "viajante" - ele acrescenta } \\
\text { informações mesmo } \\
\text { quando não são diretamente } \\
\text { pertinentes ao entendimento } \\
\text { do romance. Os "dez contos" } \\
\text { são referidos no romance } \\
\text { no contexto da loteria ganha } \\
\text { por Pádua, pai de Capitu. A } \\
\text { analogia remete a algo de fora } \\
\text { do texto: não há compra de } \\
\text { escravos em Dom Casmurro, } \\
\text { nem referência à cidade de } \\
\text { Vassouras. }\end{array}$ \\
\hline $\begin{array}{l}\text { "[...] Look-say that you're willing } \\
\text { to go to São Paulo to study law." } \\
\text { (p. 39) } \\
\text { *In the nineteenth century there } \\
\text { were no universities in Brazil. } \\
\text { Many of the elite sent their sons to } \\
\text { complete their education at either } \\
\text { of the two law schools, in São } \\
\text { Paulo or Recife. }\end{array}$ & Explicação histórica. & $\begin{array}{l}\text { No romance, a sugestão que } \\
\text { José Dias dá a Bentinho é } \\
\text { simples: estudar direito em } \\
\text { São Paulo. O tradutor chama } \\
\text { atenção, entretanto, para o } \\
\text { fato de que no Brasil do século } \\
\text { XIX não havia universidades. } \\
\text { Pode ser que haja, aqui, uma } \\
\text { comparação nas entrelinhas: } \\
\text { ao contrário da Inglaterra, } \\
\text { o Brasil ainda não possuía } \\
\text { universidades. }\end{array}$ \\
\hline $\begin{array}{l}\text { Glória Church* (p. 42) } \\
{ }^{*} \text { A small baroque church, situated } \\
\text { at the top of a hill, and a well- } \\
\text { known landmark not more than a } \\
\text { mile of two from Bento's house. }\end{array}$ & Explicação de topônimo. & $\begin{array}{l}\text { Novamente, uma espécie de } \\
\text { "dica de viajante". }\end{array}$ \\
\hline $\begin{array}{l}\left.\text { Promenade }^{*} \text { (p. } 46\right) \\
{ }^{*} \text { The Passeio Público, part of } \\
\text { which still exists, was a formal } \\
\text { garden on the edge of the water, } \\
\text { commanding an extensive view of } \\
\text { Guanabara Bay. }\end{array}$ & Explicação de topônimo. & $\begin{array}{l}\text { Um raro caso em que Gledson } \\
\text { traduziu um nome próprio de } \\
\text { topônimo - de Passeio Público } \\
\text { para "Promenade", termo } \\
\text { de origem francesa bastante } \\
\text { usado na Inglaterra. }\end{array}$ \\
\hline
\end{tabular}




\begin{tabular}{|c|c|c|}
\hline $\begin{array}{l}\text { yellow fever* (p. 106) } \\
{ }^{*} \text { Yellow fever epidemics still } \\
\text { killed thousands every summer, } \\
\text { especially in Rio de Janeiro. }\end{array}$ & $\begin{array}{l}\text { Explicação de } \\
\text { singularidade histórica. }\end{array}$ & $\begin{array}{l}\text { O uso de "still (ainda) pelo } \\
\text { tradutor pode indicar uma } \\
\text { possível comparação entre o } \\
\text { Brasil e outros lugares: talvez } \\
\text { a febre amarela já não matasse } \\
\text { tanto, àquela altura, em outras } \\
\text { localidades como no Brasil. }\end{array}$ \\
\hline $\begin{array}{l}\text { He was three years older than I, } \\
\text { the son of a lawyer from Curitiba* } \\
\text { (p. 107) } \\
{ }^{\star} \text { Curitiba is the capital of the } \\
\text { southern state of Paraná. }\end{array}$ & Explicação de topônimo. & $\begin{array}{l}\text { Explicação } \\
\text { c o n t e m p o r a n e i d a d e } \\
\text { geográfica. Não se sabe, pela } \\
\text { nota, se Curitiba já era capital } \\
\text { do Paraná na época descrita } \\
\text { pelo narrador. }\end{array}$ \\
\hline $\begin{array}{l}\text { The fashion for imitating the } \\
\text { French girls on the Rua do } \\
\text { Ouvidor, }{ }^{\star}(\mathrm{p} .109) \\
{ }^{\star} \text { The Rua do Ouvidor was the } \\
\text { central shopping street if downtown } \\
\text { Rio de Janeiro; most of the fashion } \\
\text { shops were French. }\end{array}$ & Explicação de topônimo. & $\begin{array}{l}\text { Uma visão de viajante (no } \\
\text { espaço e no tempo): onde } \\
\text { fica e como é a rua, com um } \\
\text { pormenor de sua descrição. }\end{array}$ \\
\hline $\begin{array}{l}\text { He lived in the old Campo da } \\
\text { Aclamação, and then... and } \\
\text { then...* (p. 136) } \\
{ }^{*} \text { The Campo da Aclamação was a } \\
\text { large open area near the center of } \\
\text { Rio de Janeiro, now occupied by } \\
\text { the Praça da República. }\end{array}$ & Explicação de topônimo. & $\begin{array}{l}\text { Mais um caso em que o } \\
\text { tradutor propõe uma ponte } \\
\text { entre a geografia carioca da } \\
\text { época referida pelo narrador e } \\
\text { a contemporânea, à moda dos } \\
\text { guias turísticos. }\end{array}$ \\
\hline $\begin{array}{l}\text { When we got up to Tijuca, where } \\
\text { our love-nest was, heaven took the } \\
\text { rain away and lit the stars, not } \\
\text { just the ones we know, but also } \\
\text { those which will only be discovered } \\
\text { many centuries hence.* (p. 178) } \\
\text { *Tijuca was a partly landscaped } \\
\text { forest area relatively close to } \\
\text { the center of Rio de Janeiro, } \\
\text { with romantic associations: a } \\
\text { traditional place for honeymoons. }\end{array}$ & $\begin{array}{l}\text { Explicação de topônimo } \\
\text { acrescida de uma } \\
\text { curiosidade. }\end{array}$ & $\begin{array}{l}\text { Aqui, Gledson reforça algo } \\
\text { que parece já ser sugerido no } \\
\text { texto, de modo a oferecer um } \\
\text { pouco mais de informação ao } \\
\text { leitor - o olhar de conhecedor } \\
\text { que tanto se espera de relatos } \\
\text { de viagem. }\end{array}$ \\
\hline
\end{tabular}

Dom Casmurro por John Gledson: notas de rodapé do tradutor como literatura de 75 viagem 


\begin{tabular}{|c|c|c|}
\hline $\begin{array}{l}\text { Andaraí }{ }^{*} \text { (p. 181) } \\
{ }^{*} \text { Andaraí was a middle-class } \\
\text { suburb in the foothills. }\end{array}$ & Explicação de topônimo. & $\begin{array}{l}\text { Gledson refere-se à } \\
\text { distribuição social e geográfica } \\
\text { carioca da época do romance. }\end{array}$ \\
\hline $\begin{array}{l}\text { Therefore, our political } \\
\text { constitution, which has substituted } \\
\text { a simple affirmation for an oath, is } \\
\text { profoundly moral. }{ }^{*} \text { (p. 198) } \\
\text { ^The constitution of the Brazilian } \\
\text { Republic, which replaced the } \\
\text { Empire in 1889, separated Church } \\
\text { and State, and thus did not require } \\
\text { deputies and office holders to } \\
\text { take oaths of office by religious } \\
\text { formulae. }\end{array}$ & Explicação histórica. & $\begin{array}{l}\text { Embora o dado em si esteja } \\
\text { correto, dizer que Igreja e } \\
\text { Estado foram separados no } \\
\text { Brasilinduz, inadvertidamente, } \\
\text { uma noção pouco crítica } \\
\text { da realidade político-social } \\
\text { brasileira. Ainda hoje, a } \\
\text { polêmica Igreja x Estado } \\
\text { vigora nos meios intelectuais } \\
\text { brasileiros. }\end{array}$ \\
\hline $\begin{array}{l}\left.\text { Flamengo }{ }^{*} \text { (p. } 203\right) \\
{ }^{\star} \text { Flamengo is an area of Rio de } \\
\text { Janeiro further from the center, and } \\
\text { just beyond Gloria, on Guanabara } \\
\text { Bay. Escobar has moved up in the } \\
\text { world. }\end{array}$ & 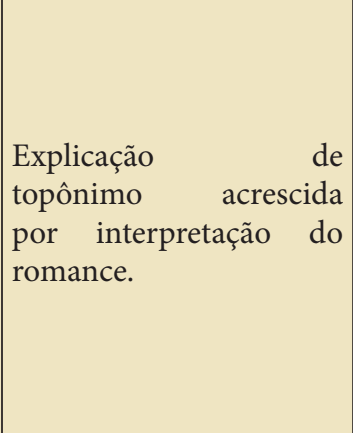 & $\begin{array}{l}\text { Esta nota sugere uma } \\
\text { interpretação: ao se mudar } \\
\text { de Andaraí para o Flamengo, } \\
\text { Escobar teria "subido" na } \\
\text { vida. O quanto isso interfere } \\
\text { positiva ou negativamente na } \\
\text { leitura leva a uma discussão } \\
\text { complexa acerca da construção } \\
\text { de sentido que cabe a cada } \\
\text { leitor durante a experiência da } \\
\text { leitura. }\end{array}$ \\
\hline $\begin{array}{l}\text { A governess from Rio Grande* (p. } \\
217 \text { ) } \\
{ }^{*} \text { Rio Grande do Sul, the } \\
\text { southernmost province of the } \\
\text { Empire, bordering on Uruguay. }\end{array}$ & Explicação de topônimo. & $\begin{array}{l}\text { Neste caso, Gledson descreve } \\
\text { o Rio Grande do Sul tal qual } \\
\text { era à época em que se passa } \\
\text { a narrativa, e não como uma } \\
\text { das } 27 \text { unidades federativas } \\
\text { brasileiras atuais. }\end{array}$ \\
\hline $\begin{array}{l}\text { aroeira and the pitanga tree (p. } \\
\text { 238) } \\
\text { *Both trees are native from Brazil: } \\
\text { the first is an ornamental tree with } \\
\text { rose-colored fruit; the second is } \\
\text { known as the Brazilian cherry, and } \\
\text { has a small orange-red edible fruit. }\end{array}$ & $\begin{array}{l}\text { Explicação de espécies } \\
\text { vegetais. }\end{array}$ & $\begin{array}{l}\text { Descreve a flora local. Aqui, } \\
\text { porém, cabe a pergunta: onde } \\
\text { e por quem, exatamente, a } \\
\text { pitangueira é considerada a } \\
\text { cerejeira brasileira? }\end{array}$ \\
\hline
\end{tabular}

Fonte: (Gledson, 1997) 
Além dos comentários já inseridos no quadro, pode-se destacar, ainda, algumas questões gerais a respeito das notas. Há uma possível falha na padronização no uso do asterisco: às vezes, são ligados a uma palavra, outras vezes, a uma frase inteira - ainda que a explicação seja, na verdade, de um só termo contido na frase. Mais relevante, entretanto, é a escolha do tradutor de transitar entre diferentes tempos históricos, o que pode gerar confusão. Há notas que explicam o país tal qual era à época em que se passa o romance, como a que cita o Rio Grande do Sul, outras que falam do Brasil do século XX, como a do Corcovado. As explicações também conduzem a uma problematização: de onde vêm esses dados? Assim, há notas que, por si só, convidariam a um estudo aprofundado sobre como o Brasil é apresentado pelo tradutor, tal qual se poderia fazer com relatos de viagem.

As notas de Gledson deixam clara a sua postura de tradutor que não se intimida ao extrapolar o espaço do texto principal, apesar de afirmar em sua introdução que manteve as notas a um mínimo possível (GLEDSON, 1997, p. xxv). Mas não é a partir do número de notas, e sim de seu objetivo de "dar alguma ideia da geografia - física e social - do Rio de Janeiro" (GLEDSON, 1997, p. xxv), que se pode traçar, mais fortemente, um paralelo entre os seus comentários e o gênero literatura de viagem.

O conteúdo que acompanha o texto principal - o paratexto, portanto - é percebido pelos leitores de maneira diferente. Enquanto informações históricas e geográficas estão na "boca" do narrador (o que ocorre em profusão em Dom Casmurro), o leitor sabe, ainda que inconscientemente, que o filtro de interpretação em questão é o olhar de Bentinho/Casmurro; nas notas, porém, essas informações passam a ser verdades, pois não se trata mais de ficção. Atrelar "verdades" à ficção pode ser um dos aspectos mais controversos das notas de rodapé, embora não as invalide - esse, aliás, é um traço comum que partilham com outros gêneros, como o jornalismo e, justamente, o da literatura de viagem. Youngs $(2013$, p. 5) ressalta essa peculiaridade quando diz que a literatura de viagem é literatura, mas nunca é totalmente ficção; por analogia, pode-se considerar que o conteúdo das notas do tradutor não são ficção, mas também não deixam de ser literatura, potencialmente se integrando ao romance de forma orgânica.

O tradutor pode assumir diversos papéis em suas notas de rodapé - o de historiador, biógrafo, crítico literário etc. Gledson, estudioso do Brasil e de Machado de Assis, deixa transparecer, por meio de suas notas, a 
intenção de contextualizar o romance na história brasileira e na paisagem do Rio de Janeiro, tal qual um viajante que apresenta, à sua maneira, um lugar aos seus leitores.

Todo relato de viagem - em forma de nota ou não - interpreta a realidade, algo que não se pode driblar; uma possível solução para que o "viajante" se posicione de maneira mais clara, contudo, pode ser a presença de referências ou indicativos como "de acordo com...", de modo a situar o conteúdo do ponto de vista teórico-ideológico e, consequentemente, explicitar o caráter informativo das notas.

\section{Considerações finais}

Este artigo abordou uma hipótese que talvez possa parecer inusitada - a de que notas do tradutor literário podem se encaixar no gênero da literatura de viagem -, propondo um cruzamento entre crítica da tradução, processo tradutório e gênero literário.

Com base em noções gerais a respeito da literatura de viagem, foram analisadas 20 notas de rodapé redigidas pelo tradutor John Gledson em seu Dom Casmurro (1997), para o qual ele adotou um projeto tradutório de cunho claramente histórico-sociológico e realista, no qual lhe pareceu produtivo ajudar o leitor a entender particularidades a respeito do Brasil. Entre essas particularidades, constam paisagens naturais e urbanas e monumentos históricos. Ao retratá-los, pode-se considerar que as notas de Gledson integram o gênero "guarda-chuva" literatura de viagem, assim reafirmando a condição do tradutor como viajante. Nesse caso, sua viagem se dá pelo espaço (Inglaterra - Brasil) e pelo tempo, já que, da última década do século XX, ele se transporta ao século XIX de Machado.

À semelhança do que ocorre com relatos de viagem, sob o olhar da crítica pós-colonial, a análise apresentada confirma que não há como o viajante escrever com neutralidade; mesmo que em uma curta nota de rodapé que se pretenda objetiva, é perceptível o olhar daquele que observa de fora, de longe - sobretudo quando se trata de um olhar central (no caso, de um tradutor inglês) sobre um local geopoliticamente periférico (o Brasil). 
Futuros estudos podem debruçar-se sobre outras notas de rodapé que acompanham a obra machadiana em inglês e sobre notas assinadas por tradutores literários em geral. O cerne da investigação está em perceber como o tradutor-viajante, ou viajante-tradutor, apresenta lugares muitas vezes desconhecidos pelos leitores e como essa apresentação pode impactar tanto o processo de leitura de literatura traduzida como a própria percepção que esses leitores terão daqueles lugares.

\section{Referências}

ASSIS, Machado de. Dom Casmurro. In: ASSIS, Machado de. Obras completas. Volume I. 9. ed. Rio de Janeiro: Nova Aguilar, 1994.

ASSIS, Machado de. Dom Casmurro. Tradução de John Gledson. Nova York: Oxford University Press, 1997.

GLEDSON, John. Notas do tradutor. In: ASSIS, Machado de. Dom Casmurro. Trad. John Gledson. Nova York: Oxford University Press, 1997.

BASSNETT, Susan. Travel Writing and Gender. In: HULME, Peter; YOUNGS, Tim (ed.). The Cambridge Companion to Travel Writing. Cambridge: Cambridge University Press, 2004. p. 225-241.

BERMAN, Antoine. A tradução e a letra ou o albergue do longínquo. Tradução de Marie-Hélène C. Torres, Mauri Furlan, Andréia Guerini. Florianópolis: PGET/UFSC, 2012.

FREITAS, Luana Ferreira de. Dom Casmurro em inglês: tradução, visibilidade e crítica. In: GUERINI, Andréia; FREITAS, Luana Ferreira de; COSTA, Walter Carlos (org.). Machado de Assis tradutor e traduzido. Florianópolis: PGET/UFSC, 2012. pp. 75-85.

GENETTE, Gérard. Paratextos editoriais. Tradução de Álvaro Faleiros. Cotia (SP): Ateliê Editorial, 2009.

GLEDSON, John. Depoimento do professor John Gledson Espaço Machado de Assis (14/10/2005). Disponível em: https://www. 
machadodeassis.org.br/abl_minisites/cgi/cgilua.exe/sys/starteffo. html infoid $=76 \&$ sid $=21 \&$ UserActiveTemplate $=$ machadodeassis. Acesso em 29/06/2021.

GLEDSON, John. Foreword. In: ASSIS, Joaquim Maria Machado de. Dom Casmurro. Nova York: Oxford University Press, 1997. p. xi-xxvii.

GLEDSON, John. Translating Machado de Assis / Traduzindo Machado de Assis. Tradução de Luana Ferreira de Freitas. Scientia Traductionis, n.14, 2013. p. 6-63.

GLEDSON, John. Machado de Assis: impostura e realismo. Tradução de Fernando Py. São Paulo: Companhia das Letras, 2005.

GLEDSON, John. Por um novo Machado de Assis - ensaios. São Paulo: Companhia das Letras, 2006.

MITTMANN, Solange. Notas do tradutor e processo tradutório: análise e reflexão sob uma perspectiva discursiva. Porto Alegre: Editora da Universidade do Rio Grande do Sul (UFRGS), 2003.

NEUMANN, Gerson Roberto. Lê-se o que se quer ler: Questões em torno da tradução cultural. In: BITTENCOURT, Rita Lenira e SCHMIDT, Rita Terezinha (org.). Fazeres indisciplinados - estudos de literatura comparada. Porto Alegre: Editora da UFRGS, 2013, p. 147-155.

PRATT, Mary Louise. Imperial Eyes: travel writing and transculturation. Londres: Routledge, 1992.

YOUNGS, Tim. Introduction: Defining the Terms. In: YOUNGS, Tim. The Cambridge Introduction to Travel Writing. Cambridge: Cambridge University Press, 2013. 